\title{
Complementary and Alternative Medicine (CAM) Competencies of Nursing Students and Faculty: Results of Integrating CAM Into the Nursing Curriculum
}

\author{
Cathryn Booth-LaForce, Ph.D., Craig S. Scott, Ph.D., Margaret M. Heitkemper, Ph.D., B. Jane \\ Cornman, Ph.D., Ming-Chih Lan, M.Ed., Eleanor F. Bond, Ph.D., and Kristen M. Swanson, \\ Ph.D. \\ University of Washington
}

\begin{abstract}
As part of the National Center for Complementary and Alternative Medicine (CAM) R25 Education Grant Program, a faculty development program for integrating CAM into the nursing curriculum was instituted in 2003-2006. The Integrating CAM program comprised a number of elements; the primary strategy included a series of 4-week didactic and experiential summer CAM "camps," attended by a total of 27 faculty members. Camps were designed to influence faculty integration of CAM material into course offerings. The Integrating CAM program was evaluated via a series of faculty and student surveys regarding CAM competencies, attitudes, and perceptions. For more than half of the faculty (out of the 43 who responded), the program yielded a moderate-to-strong influence on incorporation of CAM material into course content; and moderate-to-great increases in both enthusiasm for CAM and perceived CAM knowledge gains. Students at all levels (undergraduate, masters, doctoral; $n=$ 184) reported that their courses contained CAM content; for $70 \%$ of students, their CAM knowledge increased; for $50 \%$ of students, level of CAM interest increased. Self-reported student CAM competencies were significantly greater in 2006-2007 $(n=191)$ than in 2003-2004 $(n=143)$. Results support the strategy of broadly infusing the nursing curriculum with CAM content via faculty development.
\end{abstract}

\section{Keywords \\ Complementary medicine; Alternative therapies; Nursing curriculum; Nursing faculty; Nursing students}

\section{CAM Attitudes and Competencies of Nursing Students and Faculty: Results of Integrating CAM into the Nursing Curriculum}

The well-documented and growing use of complementary and alternative medicine (CAM; Eisenberg et al., 1998; Kessler et al., 2001), coupled with an expanding evidence base for use of some CAM therapies, have resulted in changing expectations about the need for healthcare

\footnotetext{
(c) 2010 Elsevier Inc. All rights reserved.

Corresponding author: Cathryn Booth-LaForce, Ph.D. University of Washington CHDD, 106 South Building Box 357920 Seattle, WA 98195-7920 (206) 543-8074 (206) 685-3349 (fax) ibcb@u.washington.edu.

Publisher's Disclaimer: This is a PDF file of an unedited manuscript that has been accepted for publication. As a service to our customers we are providing this early version of the manuscript. The manuscript will undergo copyediting, typesetting, and review of the resulting proof before it is published in its final citable form. Please note that during the production process errors may be discovered which could affect the content, and all legal disclaimers that apply to the journal pertain.
} 
professionals to be educated about CAM (Kreitzer, Mitten, Harris, \& Shandeling, 2002). The Institute of Medicine's Committee on the Use of Complementary and Alternative Medicine by the American Public (Institute of Medicine, 2005) has recommended that curricula for healthcare professionals incorporate information about CAM so that patients can be competently advised regarding safe alternatives for maintaining and improving health.

Within the nursing profession, the American Association of Colleges of Nursing (AACN, 1998) has outlined core competencies and necessary curricular elements of nursing education programs. Among these competencies are items such as "develop an awareness of complementary modalities and their usefulness in promoting health," and "evaluate and assess the usefulness in integrating traditional and complementary health care practices." Almost half of all state boards of nursing have officially recognized CAM as being consistent with nursing practice, and most other state boards are considering this position (Sparber, 2001).

In a number of studies, the majority of nursing faculty and students (both undergraduate and graduate) have expressed positive attitudes towards CAM, agreement with the need to learn more about the nature of CAM modalities, and a desire to learn more about effective strategies for integrating CAM knowledge into standard health care curricula (Halcón, Chlan, Kreitzer, \& Leonard, 2003; Kim, Erlen, Kim \& Sok, 2006; Laurenson, MacDonald, McCready, \& Stimpson, 2006; Melland \& Clayburgh, 2000). Clearly, incorporating information about CAM into existing nursing curricula is important (Wyatt \& Post-White, 2005), but the extent and the methods of integration are problematic $(\mathrm{Xu}, 2004)$ because most nursing faculty members lack basic essential CAM knowledge needed to develop such curricula. In some schools, CAM content has been integrated into standard nursing courses (Fenton \& Morris, 2003; Richardson, 2003). In others, specific CAM courses have been developed for undergraduate nursing students with some success (Breda \& Schulze, 1998; Melland \& Clayburgh, 2000; Pepa \& Russell, 2000; Reed, Pettigrew, \& King, 2000). However, such courses are usually dependent on a relatively small cadre of CAM-informed nurse educators. Faculty development programs are needed to ensure that information about CAM is incorporated into nursing curricula across courses and at different levels (Fenton \& Morris, 2003; Halcón et al., 2003; Kim et al., 2006; Richardson, 2003).

In 2002, the University of Washington (UW) School of Nursing received a competitive, 5-year education grant (R25 mechanism) from the National Center on Complementary and Alternative Medicine (NCCAM) at the National Institutes of Health. The purpose of the grant was to facilitate and evaluate the incorporation of CAM material into the nursing curriculum. The conceptual framework of the grant was the caring-healing paradigm, which is at the center of the nursing profession and is also consistent with the philosophical tenets of many aspects of CAM. Nursing, as "informed caring for the well-being of others" (Swanson, 1993), derives its knowledge base from nursing science as well as a broad array of related disciplines. However, nurses are rarely educated in the knowledge base of CAM, despite its widespread use. Thus, the rationale for the project was that in order for nurses to care for clients from a truly informed position it is essential for nursing schools to provide CAM content.

A total of 15 NCCAM R25 grants were awarded to nursing and medical schools in the United States. (One of these was awarded to the American Medical Student Association). All of the grants were designed to evaluate and integrate CAM content into the existing curricula (see Pearson \& Chesney, 2007). A variety of approaches were used to achieve this aim. At the University of Washington School of Nursing, R25 funding was used to focus primarily on faculty development (see Nedrow et al., 2007). This program, described in detail elsewhere (Cornman, Carr, \& Heitkemper, 2006), consisted of CAM "Camp" or CAMp. CAMp was a 4-week summer educational program held in collaboration with Bastyr University. The curriculum included didactic and experiential learning about the concepts, philosophies, 
evidence base, and practice of various CAM modalities, including mind-body interventions (meditation, yoga), biologically based practices (botanicals, special dietary approaches), manipulative methods (chiropractic, massage), and energy therapies (Qi Gong, therapeutic touch). Additionally, whole medical systems (Traditional Chinese Medicine, Ayurvedic Medicine, Homeopathy) were discussed in terms of their cultural context and component modalities. Licensed practitioners provided the didactic and experiential content.

From 2003-2006, a total of 27 faculty from the School of Nursing attended CAMp representing all three levels of instruction - undergraduate, masters, and doctoral. A significant requirement for CAMp participation was that faculty develop written documentation, justification, and plans for integrating CAM material into their existing courses. Faculty attending CAMp received $1 / 2$ month salary reimbursement, a supplement to their academic year salary. They did not pay tuition, nor did they receive CEUs or academic credit.

With the intention of reaching an audience of faculty and students beyond the "CAMpers," CAM Brown Bag presentations were sponsored by the R25 program for the five years of the grant, at least once per academic quarter. No CEUs or academic credits were given for these Brown Bag sessions. Presentations, which included topics such as Ayurvedic Medicine, Chiropractic Care, Therapeutic Touch, Qi Gong, and Yoga, were open to all faculty, staff, and students from the School of Nursing, as well as other disciplines. Attendance varied from 5-30 participants per session. Additionally, an introductory didactic and experiential course for graduate students, "CAM, Integrative Health Care, and Wellness," was developed and taught by two of the faculty on the R25 leadership team. The course, which was open to students across the health sciences, was offered twice for a total of 20 students, 15 of whom were from the School of Nursing. These enrollment numbers are typical for graduate-level elective courses in the School.

It is worth noting that all of these activities were conducted in the context of a supportive leadership environment. Thus, the provision of educational and faculty development opportunities, within this supportive context, yielded additional unanticipated opportunities (e.g., weekly meditation and Qi Gong sessions; CAM-related research grants and dissertations; new collaborations with faculty at Bastyr University and the UW School of Medicine-also the recipient of an NCCAM R25 grant).

\section{Evaluation}

To evaluate the impact of the faculty development program on CAM attitudes and competencies, nursing faculty and students completed a series of surveys regarding CAM competencies, attitudes and perceptions.

\section{Participants and Method}

Participants were undergraduate and graduate students (Masters and Ph.D.) and faculty members from the University of Washington School of Nursing (UW SON). Human Subjects approval was obtained for a voluntary, anonymous survey series that focused on CAM competencies, attitudes and perceptions. During the spring of every year from 2003 to 2007, undergraduate BSN students were asked to complete a survey at program entry and at year's end. The year-end surveys were administered during core classes. Graduate students completed the survey in class during 2007. Faculty (teaching and research faculty at all levels-Lecturers through full Professors) were asked to complete a comparable retrospective survey in a faculty meeting during the spring of 2007. Potential respondents who had not completed their respective surveys in class or during the faculty meeting were asked to complete them via a web-based version. By using these methods, we were able to achieve excellent response rates 
(see Results), especially in comparison with other surveys conducted entirely via web-based methods (e.g., distance learning surveys).

\section{Measures}

All surveys included a series of 11 questions designed to assess CAM competencies, as well as additional questions about CAM attitudes and perceptions, including the impact of the R25 grant. These questions were adapted from a survey designed by the Rush University School of Nursing (Zeller et al., 2002). Although reliability and validity data were not available for the survey, the questions were deemed appropriate for the purpose of the study. The specific questions and competencies are shown in Tables 1-3. The competencies were rated on a 6point scale, from $1=$ "not at all" to $6=$ "to a great extent."

\section{Hypotheses}

We hypothesized that (a) both students and faculty would have positive attitudes about CAM and about the incorporation of CAM content into the curriculum, (b) undergraduate students' CAM competencies would increase from the early years of the grant to later years, (c) graduate students would have higher CAM competency ratings than would undergraduate students, and (d) faculty CAM competencies would be higher than student competencies.

\section{Results}

Faculty attitudes-Table 1 shows responses to questions from the faculty survey (response rate $=49 \%$ ). Slightly less than half of the faculty respondents indicated that they had incorporated CAM content into their courses in the last 3 years. Although $8 \%$ of faculty respondents indicated that they would have included CAM content anyway, 56\% indicated that the R25 grant had had a moderate-to-strong influence on their incorporation of CAM content into their course offerings. Most nursing faculty respondents (60\%) felt that the UW SON coverage of CAM was "just right" while the remainder of the faculty indicated that "not enough" coverage was provided. No respondents thought that CAM coverage was too extensive.

A total of $56 \%$ of the nursing faculty respondents reported that their CAM knowledge had increased during the previous 3 years either to a moderate or to a great extent. Fifty-four percent of faculty respondents reported increases in enthusiasm for information about CAM either to a moderate or to a great extent.

Student attitudes-Most students at all levels (80\%) indicated that their courses contained CAM content; $97 \%$ felt this was appropriate (see Table 2; response rate $=32 \%$ ). CAM knowledge increased for $70 \%$ of the students since coming to the UW SON; level of interest in information about CAM increased for $50 \%$ of the student respondents.

Students' CAM competencies-Descriptive statistics for undergraduate students on CAM competency items and $t$-test comparisons of responses between 2003-04 and 2006-07 are shown in Table 3 (response rate $=38 \%$ for $2003-2004 ; 49 \%$ for 2006-2007). For all items, students in the later years had significantly higher self-reported competence scores than did students in the earlier years. The items with the highest scores ( 2.5 and above) in the later years were: (a) evaluate various health and healing practices of populations with diverse cultural backgrounds, (b) identify scientific and consumer information CAM resources, (c) evaluate the quality of CAM research literature and consumer information, (d) incorporate, with cultural sensitivity, assessment of CAM practices into patient history, (e) practice CAM approaches for self-care, (f) evaluate and discuss with patients drug/CAM interactions, and (g) describe how one or more CAM therapies influence the health status of individuals. Self-reported competencies with relatively lower scores were: (a) describe the theoretical basis for selected 
CAM therapies, (b) discuss the training, licensing, and credentialing of CAM practitioners, (c) provide information to patients about use of CAM therapies, and (d) describe ethical, societal, and cultural issues pertaining to CAM therapies.

Students at various levels were compared on self-reported CAM competencies in the 2007 data, shown in Table 4 (response rate $=37 \%$ ). Undergraduate seniors, masters,, and Ph.D. students were compared on each item via one-way analyses of variance, using a critical value of $p<.05$. None of these analyses yielded significant differences between student levels, except for one item-Describe how one or more CAM therapies influence the health status of individuals, $F(2,181=4.58, p=.01)$. A post-hoc LSD test indicated that undergraduate students scored significantly lower on this item than did masters and Ph.D. students.

Faculty CAM competencies-Descriptive statistics for faculty CAM competencies in 2007 are shown in Table 5, along with a comparison of faculty and student (all levels) competencies via $t$-tests. As would be expected, faculty had higher mean scores than did students on all items, but tests did not yield statistically significant differences on four items: (a) evaluate various health and healing practices of populations with diverse cultural backgrounds, (b) incorporate, with cultural sensitivity, assessment of CAM practices into patient history, (c) evaluate and discuss with patients drug/CAM interactions, and (d) discuss the training, licensing, and credentialing of CAM practitioners.

\section{Discussion}

The results indicated that the R25 Integrating CAM program had a positive impact on the incorporation of CAM material throughout the curriculum. Almost half of the nursing faculty included CAM content in their courses following the initiation of the program. Less than $10 \%$ indicated that they would have done it anyway without the R25, and more than half indicated that the program had a moderate-to-strong influence on their incorporation of CAM content. Most students reported that courses contained CAM content and that this was appropriate. Thus, we conclude that the program was successful in infusing the existing curriculum with CAM material via faculty education at CAMp and other learning opportunities.

Our first hypothesis was that both students and faculty would have generally positive attitudes about CAM and the incorporation of CAM content into the UW SON curriculum. Results indicated that virtually all of the students (97\%) believed that the inclusion of CAM material was appropriate, and all surveyed faculty members indicated that the amount of CAM coverage in courses was either "just right" or "not enough." These results are comparable to findings from other surveys of nursing students and faculty. For example, Halcón et al. (2003) found that $98-99 \%$ of faculty and students agreed that clinical care should integrate the best of CAM with conventional health care; Melland and Clayburgh (2000) found that $82 \%$ of nursing students agreed that it is important for healthcare professionals to understand CAM therapies.

Additionally, for 50\% of the students in the UW study, interest in CAM increased, and 54\% of the faculty experienced a moderate-to-great increase in enthusiasm for CAM. Together, both the attitudes toward inclusion of CAM into the curriculum and the increases in CAM interest support our first hypothesis and reflect our expectations for the success of the program. However, it should be noted that the interest/enthusiasm results may have underestimated positive attitudes toward CAM because respondents with either an initial high or low level of enthusiasm or interest could have experienced "no" or "a little" increase in interest.

The second hypothesis was that undergraduate students' CAM competencies would increase from the early to the later years of the program. In fact, competencies were significantly higher for every item in the later years, and in 2007 , the great majority of the students indicated that 
their CAM knowledge had increased since enrollment in the UW SON. We believe that these increases in competence reflect the curricular changes resulting from faculty education efforts, and provide additional support for our relatively indirect method of changing the curriculum. However, it should be noted that even though students' CAM competencies increased over the years of the program, the mean values for the later years were over 3.0 (a moderate level of self-perceived competence) for only 3 of the 11 items, which were rated on a scale from 1 to 6. These data indicate that there is still room for improvement. That said, examination of the four items that received especially low ratings (under 2.5) - (a) describe the theoretical basis for selected CAM therapies, (b) discuss the training, licensing, and credentialing of CAM practitioners, (c) provide information to patients about use of CAM therapies, and (d), describe ethical, societal, and cultural issues pertaining to CAM therapies-did not yield a particular "theme" that would provide specific guidance about improving curricular material. Moreover, lack of comparable data from other nursing schools incorporating CAM material contributes to uncertainty about the magnitude of increases in CAM competencies we should have expected. Regardless, we view the significant increase in competencies over time in our program to be an indicator of success.

The third hypothesis was that graduate students would have higher CAM competency ratings than would undergraduate students. This hypothesis was not supported, as graduate students had significantly higher scores on only one item. Although it is not clear why competencies did not vary by student level, it could be that the items were worded in a general enough way so that students at the graduate level did not have the means to indicate higher levels of competence.

The final hypothesis was that faculty CAM competencies would be higher than student competencies. Although faculty scores were significantly higher than students' scores on 7 items, significant differences were not found for 4 items. Once again, a theme did not emerge from these four items on which the groups did not differ: (a) evaluate various health and healing practices of populations with diverse cultural backgrounds, (b) incorporate, with cultural sensitivity, assessment of CAM practices into patient history, (c) evaluate and discuss with patients drug/CAM interactions, and (d) discuss the training, licensing, and credentialing of CAM practitioners. Nonetheless, the results for the majority of the competencies support the hypothesized differences. Of particular note is that for 9 of the 11 items, faculty had mean scores that were above 3.0 on a 6-point scale, indicating moderate to very high perceived competence. Given that the great majority of the faculty indicated that their level of CAM knowledge increased in the last 3 years, this is not surprising. Although it is impossible to know the extent to which their knowledge would have increased without the R25 program, faculty attributions of program impact suggest the significance of the R25 program.

\section{Limitations}

A number of limitations of the study should be noted. First, it was not possible to perform longitudinal analyses on data from the same students over time because we did not have identifiable data, which could have affected results. Second, differences in CAM attitudes and competencies from the earlier years of the grant to the later years could have been a function, in part, of changing public attitudes about CAM, rather than being due entirely to our efforts to infuse CAM into the nursing curriculum. Third, changes in attitudes and competencies could not be linked with specific curricular elements because faculty participating in CAMp could have incorporated CAM material into their courses in many different ways. Further, faculty who did not participate in CAMp could have added CAM material to their courses because of "second order change" - meaning the general atmosphere in the School of Nursing changed to one of greater CAM acceptance and interest as an indirect result of the R25 grant. Finally, it is challenging to compare the evaluation results in the present report with those of other CAM 
programs because standard evaluation tools for such programs do not exist, even among the group of funded R25 programs (Stratton, Benn, Lie, Zeller, \& Nedrow, 2007).

\section{Other strategies}

The primary emphasis of the R25 grant at the University of Washington School of Nursing was on integrating CAM via faculty development, with particular focus on the indirect infusion of CAM into the curriculum via faculty participation in CAMp during the summer. Several other strategies for enhancing health-care professionals' attitudes about CAM have been proposed and tested. For example, in a single-site study with 123 medical residents, family medicine residents, and $3^{\text {rd }}$ and $4^{\text {th }}$ year medical students, a case-based, web-based program was found to increase knowledge about, and attitudes towards CAM therapies (Cook, Gelula, Lee, Bauer, Dupras, Schwartz 2007). However, of the 123 participants enrolled only 89 completed the course, suggesting that interest in CAM content delivered in this format may not be appealing to all learners. Regardless, one advantage of a web-based program is that it is more sustainable than programs depending on the continuing interest and expertise of particular faculty members, and sustainability is a significant issue in attempting to integrate CAM into an existing curriculum (Sierpina et al., 2007).

Another strategy is to develop specific CAM modules or required coursework so that all students in the health professions receive CAM content as part of their education. This strategy has been used in nursing to some extent (e.g., Breda \& Schulze, 1998; Melland \& Clayburgh, 2000; Pepa \& Russell, 2000; Reid et al., 2000), but a significant issue is that the typical curriculum for nursing students and those in other health professions is already very crowded without adding CAM material (Lee et al., 2007; Sierpina et al., 2007).

\section{Conclusions}

The strategy we used in the UW School of Nursing to integrate CAM into the curriculum appeared to be beneficial in terms of changing CAM attitudes and increasing competencies for both students and faculty. Although specific CAM curricular elements could not be tracked and linked with these changes, the advantage of this indirect strategy of infusing the curriculum with CAM material is that a significant number of faculty members with varied teaching responsibilities at all levels of instruction were able to participate in CAMp and then to use what they had learned to design curricular changes. Even small changes within a variety of courses, compared with a stand-alone CAM-focused course, may have an equally significant impact on students. Comparison of methods for faculty development and for teaching CAM material would be the logical next step in evaluating the best methods of ensuring that future health-care professionals attain the recommended level of expertise (Institute of Medicine, 2005; Kreitzer et al., 2002) so that patients can receive competent advice about CAM.

The NCCAM R25 funding was a time-limited opportunity, but the School's commitment to including CAM content remains strong. In addition to sustaining the changes that have been incorporated into existing courses, a graduate certificate program in CAM was developed and implemented in 2006 as a direct result of the R25 grant. Additional opportunities to fund and sustain CAM programs within the School are being pursued by a core group of faculty, in recognition of the importance of expanding the gains achieved.

\section{References}

American Association of Colleges of Nursing. The essentials of baccalaureate education for professional nursing practice. 1998 [March 11, 2008]. from http://www.aacn.nche.edu/education/pdf/BaccEssentials98.pdf

Breda KL, Schulze MW. Teaching complementary healing therapies to nurses. Journal of Nursing Education 1998;37:394-397. [PubMed: 9865893] 
Cook DA, Gelula MH, Lee MC, Bauer BA, Dupras DM, Schwartz A. A web-based course on complementary medicine for medical students and residents improves knowledge and changes attitudes. Teaching and Learning in Medicine 2007;19:230-238. [PubMed: 17594217]

Cornman BJ, Carr CA, Heitkemper MM. Integrating CAM into nursing curricula: CAM camp as an educational intervention. Explore 2006;2:226-231. [PubMed: 16781645]

Eisenberg DM, Davis RB, Ettner SL, Appel S, Wilkey S, Rompay V, Kessler RC. Trends in alternative medicine use in the United States, 1990-1997. Journal of the American Medical Association 1998;280:1569-1575. [PubMed: 9820257]

Fenton MV, Morris DL. The integration of holistic nursing practices and complementary and alternative modalities into curricula of schools of nursing. Alternative Therapies in Health and Medicine 2003;9:62-67. [PubMed: 12868254]

Halcón LL, Chlan LL, Kreitzer MJ, Leonard BJ. Complementary therapies and healing practices: Faculty/ student beliefs and attitudes and the implications for nursing education. Journal of Professional Nursing 2003;19:387-397. [PubMed: 14689396]

Institute of Medicine. Complementary and alternative medicine in the United States. National Academy of Sciences Press; Washington, DC: 2005.

Kessler RC, Davis RB, Foster DF, Van Rompay MI, Walters EE, Wilkey SA, Kaptchuk TJ, Eisenberg DM. Long-term trends in the use of complementary and alternative medical therapies in the United States. Annals of Internal Medicine 2001;135:262-268. [PubMed: 11511141]

Kim SS, Erlen JA, Kim KB, Sok SR. Nursing students' and faculty members' knowledge of, experience with, and attitudes toward complementary and alternative therapies. Journal of Nursing Education 2006;45:375-378. [PubMed: 17002085]

Kreitzer MJ, Mann D, Lumpkin M. CAM competencies for the health professions. Complementary Health Practice Review 2008;13:63-72.

Kreitzer MJ, Mitten D, Harris I, Shandeling J. Attitudes toward CAM among medical, nursing, and pharmacy faculty and students: A comparative analysis. Alternative Therapies in Health and Medicine 2002;8:44-53. [PubMed: 12440838]

Laurenson M, MacDonald J, McCready T, Stimpson A. Student nurses' knowledge and attitudes toward CAM therapies. British Journal of Nursing 2006;15:612-615. [PubMed: 16835530]

Lee MY, Benn R, Wimsatt L, Cornman J, Hedgecock J, Gerik S, Zeller J, Kreitzer MJ, Allweiss P, Finklestein C, Haramati A. Integrating complementary and alternative medicine instruction into health professions education: Organizational and instructional strategies. Academic Medicine 2007;82:939-945. [PubMed: 17895652]

Melland HI, Clayburgh TL. Complementary therapies: Introduction into a nursing curriculum. Nurse Educator 2000;25:247-250. [PubMed: 16646204]

Nedrow AR, Heitkemper M, Frenkel M, Mann D, Wayne P, Hughes E. Collaborations between allopathic and complementary and alternative medicine health professionals: Four initiatives. Academic Medicine 2007;82:962-966. [PubMed: 17895657]

Pearson NJ, Chesney MA. The CAM education program of the National Center for Complementary and Alternative Medicine: An overview. Academic Medicine 2007;82:921-926. [PubMed: 17895649]

Pepa CA, Russell CA. Introducing complementary/alternative strategies in a baccalaureate curriculum. Nursing \& Health Care Perspectives 2000;21:127-129. [PubMed: 11220853]

Reed FC, Pettigrew AC, King MO. Alternative and complementary therapies in nursing curricula. Journal of Nursing Education 2000;39:133-139. [PubMed: 10727097]

Richardson SF. Complementary health and healing in nursing education. Journal of Holistic Nursing 2003;21:20-35. [PubMed: 12666613]

Sierpina VS, Schneeweiss R, Frenkel MA, Bulik R, Maypole J. Barriers, strategies, and lessons learned from complementary and alternative medicine curricular initiatives. Academic Medicine 2007;82:946-950. [PubMed: 17895653]

Sparber, A. State boards of nursing and scope of practice of registered nurses performing complementary therapies.. The Online Journal of Issues in Nursing. 2001 [March 11, 2008]. Manuscript 10. from http://www.nursingworld.org/MainMenuCategories/ANAMarketplace/ANAPeriodicals/OJIN/ TableofContents/Volume62001/Number2May31/CmplementaryTherapiesReport.aspx 
Stratton TD, Benn RK, Lie DA, Zeller JM, Nedrow AR. Evaluating CAM education in health professions programs. Academic Medicine 2007;82:956-961. [PubMed: 17895655]

Swanson KM. Nursing as informed caring for the well-being of others. Image: Journal of Nursing Scholarship 1993;25:352-357.

Wyatt G, Post-White J. Future direction of complementary and alternative medicine (CAM) education and research. Seminars in Oncology Nursing 2005;21:215-224. [PubMed: 16092810]

$\mathrm{Xu}$ Y. Complementary and alternative therapies as philosophy and modalities: Implications for nursing practice, education, and research. Home Health Care Management \& Practice 2004;16:534-537.

Zeller JM, Downie P, Suhayda R, Keithley J, Swanson B, Terrado M, Scorza E, Willis L. CAM education program for nursing. Proceedings of the Midwest Nursing Research Society 2002:73. 


\section{Table 1}

CAM Survey Results, Faculty Attitudes, 2007 ( $n=43$ )

\begin{tabular}{|c|c|c|c|c|c|}
\hline Question & & Yes & \multicolumn{2}{|c|}{ No } & \\
\hline \multicolumn{2}{|c|}{ During the past 3 years, have you incorporated any additional CAM content into SON courses? } & $47.6 \%$ & 52. & $4 \%$ & \\
\hline Question & Not enough & \multicolumn{2}{|c|}{ Just right } & Too much & \\
\hline Which of the following best describes the current UW SON coverage of CAM? & $39.5 \%$ & \multicolumn{2}{|c|}{$60.5 \%$} & $0.0 \%$ & \\
\hline Question & \multicolumn{3}{|c|}{ Done Anyway } & Slight & Moderate \\
\hline $\begin{array}{l}\text { Did the Integrating CAM SON R25 grant influence your incorporation of additio } \\
\text { content into SON courses? }\end{array}$ & hal CAM & \multicolumn{2}{|c|}{$8.3 \%$} & $36.1 \%$ & $13.9 \%$ \\
\hline \multicolumn{2}{|l|}{ Question } & None & Little & Moderate & Great \\
\hline \multicolumn{2}{|l|}{ During the past 3 years, has your level of CAM knowledge increased? } & $.6 \%$ & $32.6 \%$ & $25.6 \%$ & $30.2 \%$ \\
\hline \multicolumn{2}{|l|}{ During the past 3 years, to what extent has your level of enthusiasm for CAM increased? } & $.4 \%$ & $22.0 \%$ & $22.0 \%$ & $31.7 \%$ \\
\hline
\end{tabular}


Table 2

CAM Survey Results, Students’ Attitudes-All Levels, 2007 ( $\mathrm{n}=184$ )

\begin{tabular}{lccc}
\hline Question & Yes & No \\
\hline Have any of your UW SON courses contained CAM content? & $79.9 \%$ & $20.1 \%$ \\
In your opinion, is it appropriate that some SON courses contain information about CAM? & $96.9 \%$ & $3.1 \%$ \\
\hline & & & \\
\hline Question & Decreased & No Change & Increased \\
\hline Since coming to the UW SON has your CAM knowledge changed? & $1.1 \%$ & $28.8 \%$ & $70.1 \%$ \\
Since coming to the UW SON has your level of interest in CAM changed? & $1.6 \%$ & $47.9 \%$ & $50.5 \%$ \\
\hline
\end{tabular}




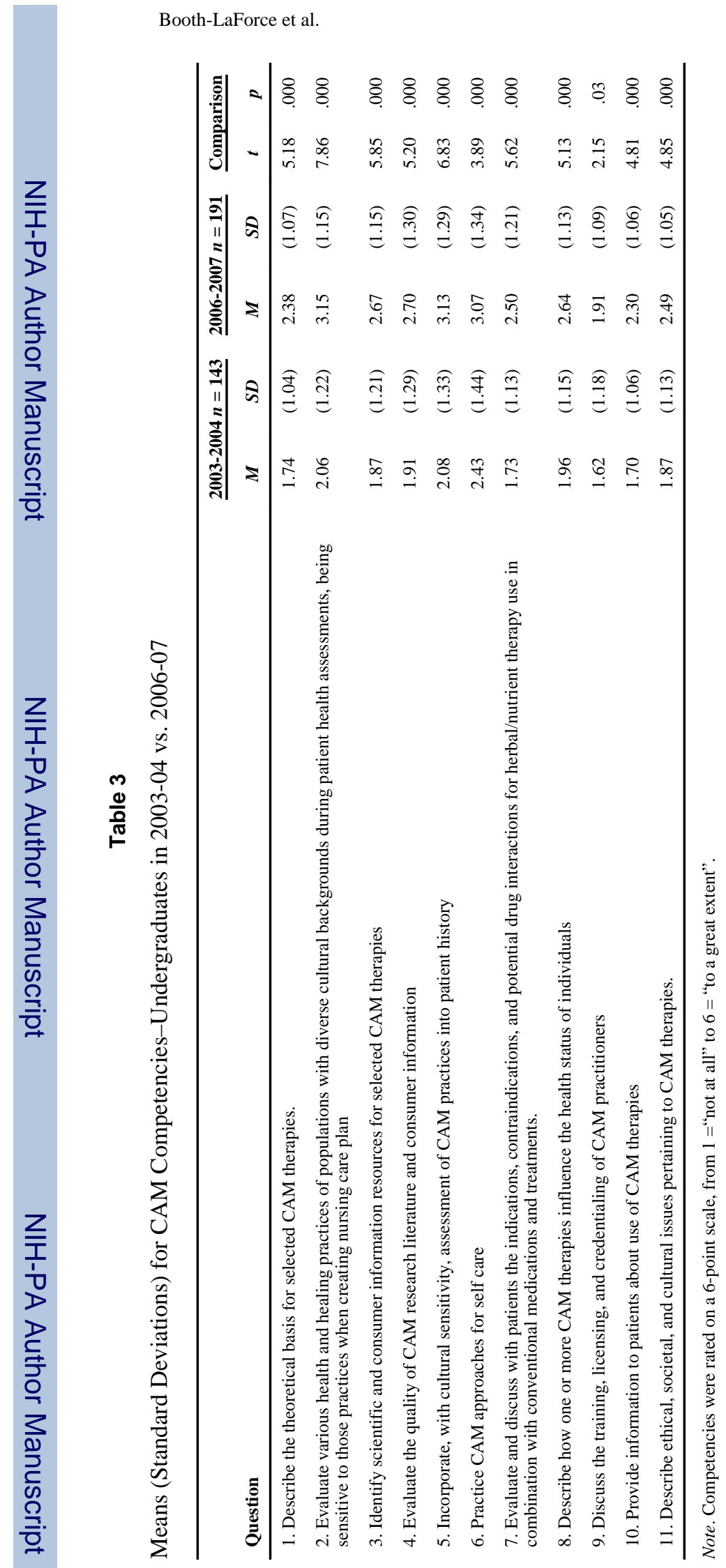

Page 12 


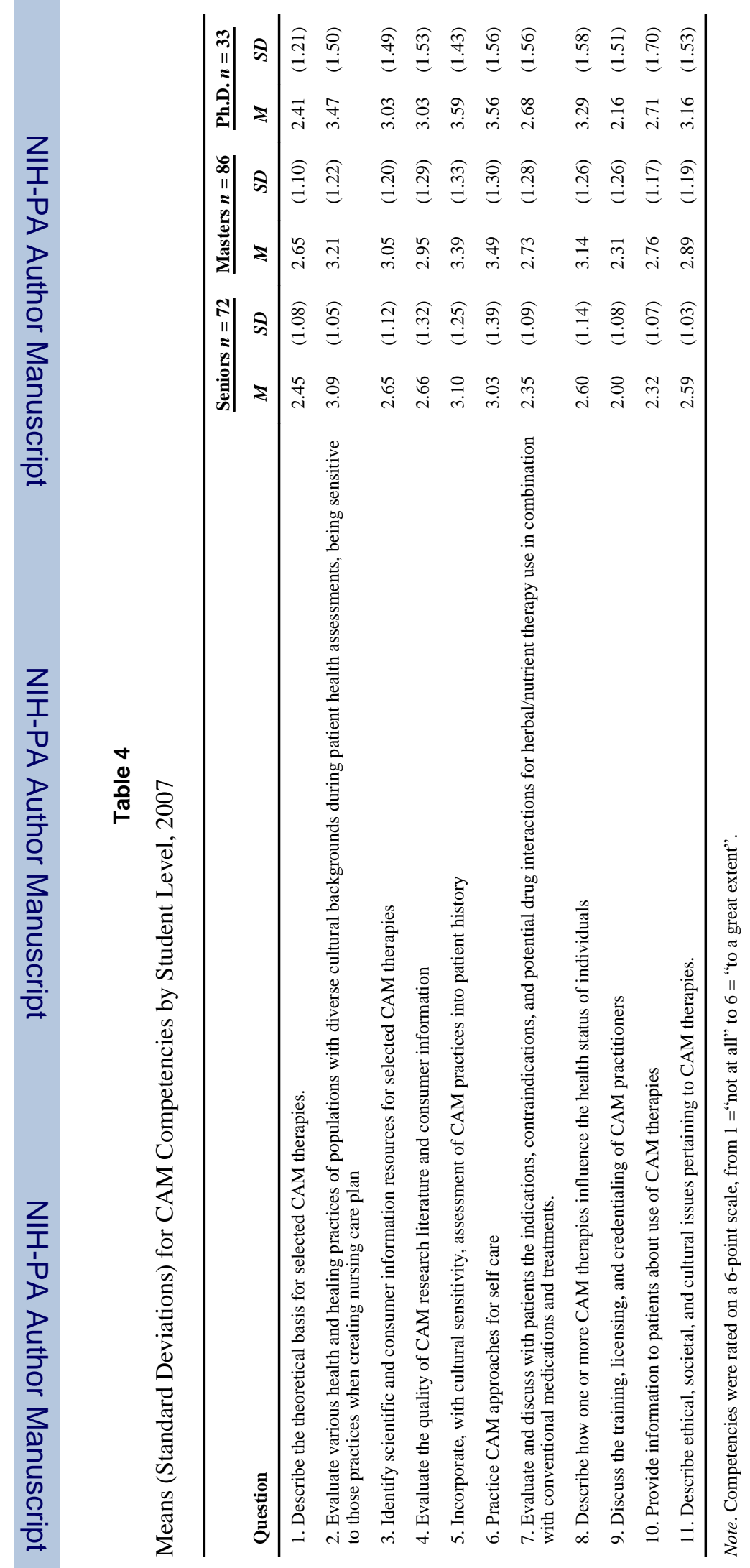

J Prof Nurs. Author manuscript; available in PMC 2011 September 1. 


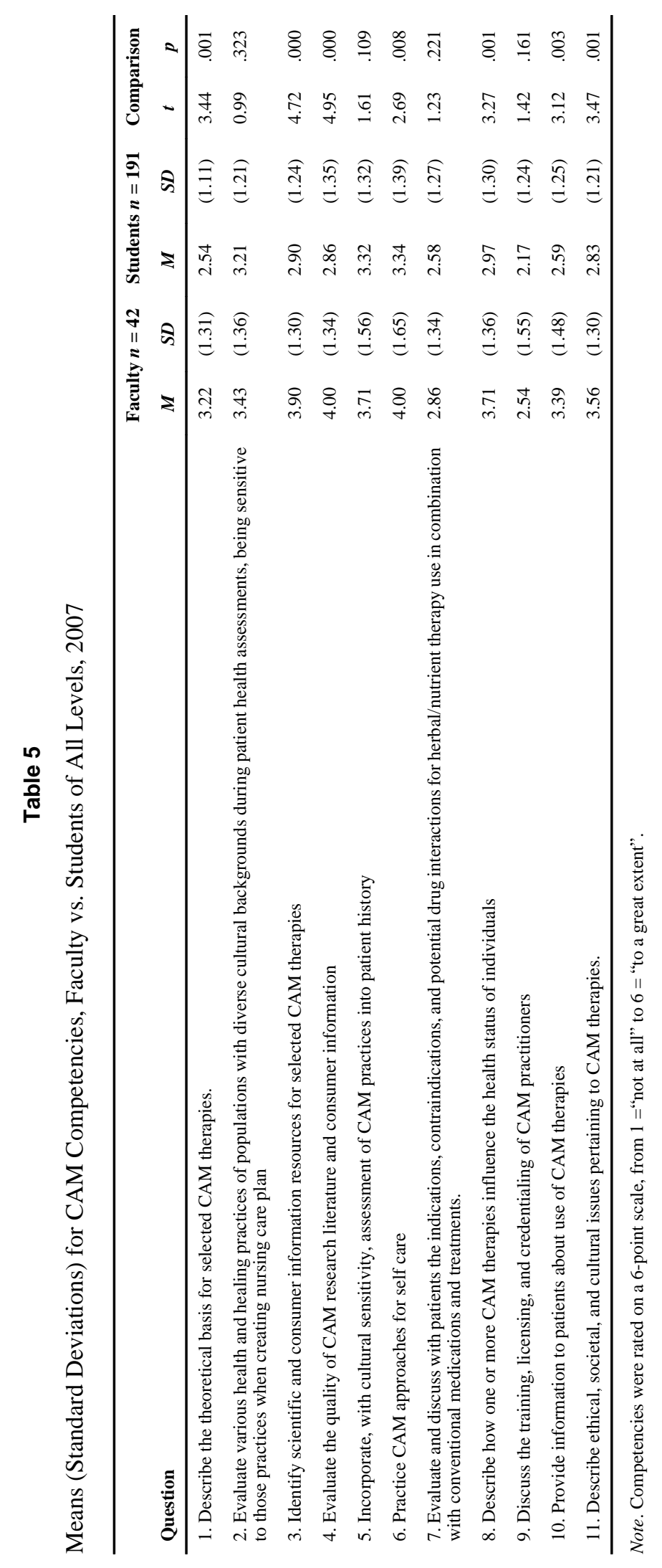

J Prof Nurs. Author manuscript; available in PMC 2011 September 1. 